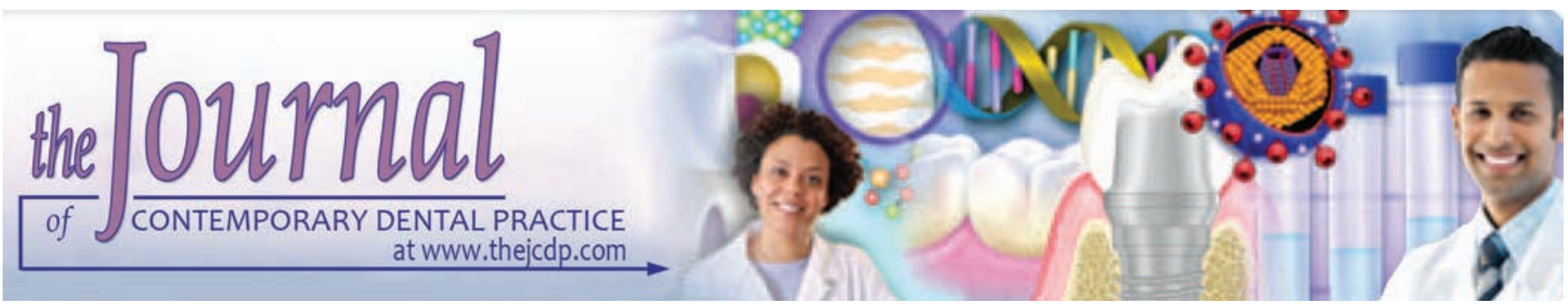

\title{
Association between Cheiloscopic Patterns and ABO Blood Groups among South Indian Population
}

\author{
${ }^{1}$ Sneha Khanapure, ${ }^{2} \mathrm{HG}$ Suhas, ${ }^{3}$ Shrudha Potdar, ${ }^{4}$ George Sam, ${ }^{5} \mathrm{CB}$ Sudeep, ${ }^{6} \mathrm{MR}$ Arjun
}

\begin{abstract}
Background: Human beings have few characteristics that are unique from others. Lip prints are one of such feature. They are not changed throughout the life and are not influenced by injuries, diseases, or environmental changes. According to the various antigen-antibody reactions in the bloodstream, different individuals have specific blood groups.
\end{abstract}

Aim: To study the distribution of lip print patterns among individuals with different $A B O$ and $\mathrm{Rh}$ blood groups and also to know the relation between their characters and blood groups.

Materials and methods: In the present study, lip prints were collected randomly from 85 individuals, and their blood group matching was performed. This is to identify the most common lip print type and to know any association between lip print types and blood groups. Tsuchihashi's classification of lip prints was used to compare with the ABO and Rh blood grouping systems.

Results: It was observed that in individuals with $\mathrm{B}+, \mathrm{A}+$, and O- blood groups, predominant pattern was Type IV and individuals having blood group $\mathrm{O}+$ and $\mathrm{AB}+$ common lip print pattern was Type II.

\footnotetext{
${ }^{1}$ Department of Public Health Dentistry, Maharashtra Institute of Dental Sciences and Research, Latur, Maharashtra, India

${ }^{2}$ Department of Oral Pathology and Microbiology, Pariyaram Dental College, Kannur, Kerala, India

${ }^{3}$ Department of Preventive Dental Sciences, College of Dentistry Qassim Private Colleges, Al Qassim, Kingdom of Saudi Arabia

${ }^{4}$ Department of Preventive Dental Sciences, College of Dentistry Prince Sattam bin Abdul Aziz University, Al Kharj, Kingdom of Saudi Arabia

${ }^{5}$ Department of Public Health Dentistry, Sree Anjaneya Institute of Dental Sciences, Kozhikode, Kerala, India

${ }^{6}$ Department of Periodontics, Sree Anjaneya Institute of Dental Sciences, Kozhikode, Kerala, India

Corresponding Author: Sneha Khanapure, Department of Public Health Dentistry, Maharashtra Institute of Dental Sciences and Research, Latur, Maharashtra, India, e-mail: dr.snehack@ yahoo.in
}

Conclusion: This study showed strong association between lip print patterns and ABO blood groups as some blood groups were not included in statistical analysis; further studies including larger sample are essential to substantiate the results.

Clinical significance: Correlating lip print with blood group helps in identification of the suspects. Along with lip prints, another biological record that remains unchanged throughout the lifetime of a person is the blood group. Determining the blood group of a person from the samples obtained at the site of crime and also recovering lip prints from site can help identify a person.

Keywords: Blood groups, Cheiloscopy, Forensic odontology, Identification.

How to cite this article: Khanapure S, Suhas HG, Potdar S, Sam G, Sudeep CB, Arjun MR. Association between Cheiloscopic Patterns and ABO Blood Groups among South Indian Population. J Contemp Dent Pract 2017;18(7):596-600.

Source of support: Nil

Conflict of interest: None

\section{INTRODUCTION}

Identification of person has an important part in the investigation of the unidentified body in mass disaster or criminal suspects, also for recognizing missing persons. In this situation, deoxyribonucleic acid profiling, fingerprints, osteology, and odontology have an important role. In recent times, even lip prints have been identified as an important tool in forensic odontology. ${ }^{1}$ Lips surround oral cavity, which is covered externally by skin and internally by mucosa. Skin lining the lip has characteristic patterns called lip prints. Like fingerprints, lip prints are also different for every individual, such as fingerprinting except in monozygotic twins. Hence, lip prints can be used in forensic odontology as it remains unchanged throughout the life of a person ${ }^{2}$ and also it recovers after undergoing trauma and different pathologies. ${ }^{3}$

Cheiloscopy studies carried out in India showed that there is a dominance of certain patterns in different populations. This will be helpful in person identification. ${ }^{4}$ 
Lip prints are also found to differ according to the racial origin of a person. ${ }^{5}$ However, most forensic investigators are not aware that lip prints are used in identification of person. Hence, further reports are needed to show the importance of cheiloscopy in forensic identification.

Yet another biological record that remains unchanged throughout the lifetime of a person is the blood group. Determining the blood group of a person from the samples obtained at the site of crime helps identify a person.

Hence, blood itself is an extremely important entity in the medicolegal practice, which alone or along with lip prints can play an important role to unfold different criminal problems. Landsteiner classified blood groups under the $\mathrm{ABO}$ blood group system. ${ }^{6}$

This study tries test hypothesis, "there is correlation between blood groups and lip print patterns of person."

\section{MATERIALS AND METHODS}

This study is a cross-sectional study done on students, teaching, and nonteaching staff of a dental college at Virajpet. Ethical consent was acquired from the Institutional Review Board. Written informed consent was taken from all the study participants. Single examiner was trained and calibrated to record and analyze lip print patterns. Blood group analysis was done by a single trained laboratory technician. Sampling was done using simple random sampling. Sample size calculation, i.e., $\mathrm{n}$ $=85$, was done using following formula:

$$
\mathrm{n}=\frac{\mathrm{N}}{1+\mathrm{Ne}^{2}}
$$
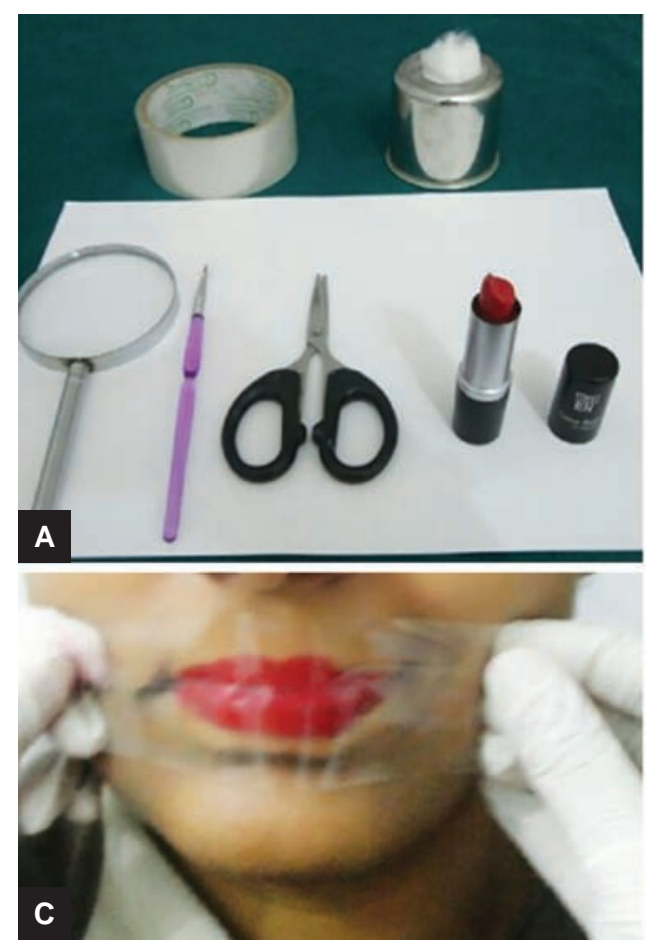

Figs 1A to D: Recording of lip prints $\mathrm{n}=$ Size of sample,

$\mathrm{N}=$ Total population,

$\mathrm{e}=$ Level of precision.

Participants were randomly selected from each group, i.e., students, teaching, and nonteaching staff of college. Individuals above 18 years of age with absolute normal lips were included in the study, whereas individuals with lip pathology were excluded from the study.

As shown in Fig. 1A, materials used to record lip prints were dark-colored lipstick (Street Wear 32), cellophane tape, white paper, scissors, magnifying lens, gloves, and tissue paper and for blood group recording were glass slide and anti-A and anti-B sera.

\section{Recording of Lip Prints}

As shown in Fig. 1B, for recording of lip prints, individuals were made to sit comfortably in an erect position. Lips of the individuals were cleaned with tissue paper before the procedure. Dark-colored lipstick was applied evenly using the application brush. Transparent cellophane about $15 \mathrm{~cm}$ neat strip and the sticky portion of strip was placed over the lips (Fig. 1C). The lip impression was made in the normal resting position by pressing it evenly from center to the corners of the lips. Later, the imprinted strip was removed in a single stroke and later placed onto a white paper for permanent record (Fig. 1D). Print procured was examined using a magnifying lens to confirm whether the print has been properly reproduced. As shown in Fig. 2, while studying the lip prints, for overall lip print pattern, as anticipated by Sivapathasundharam et al, ${ }^{2}$ the
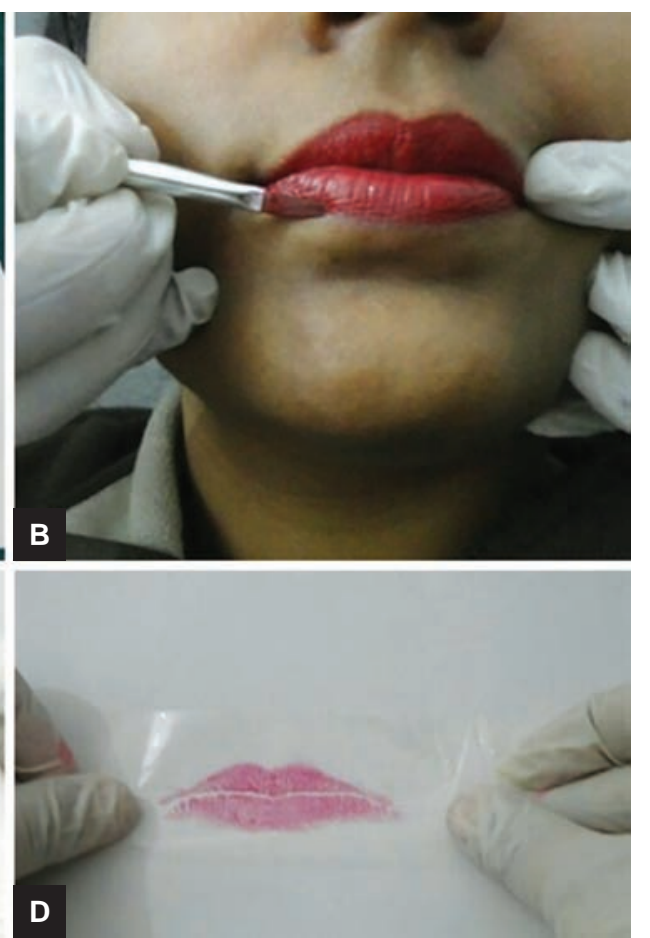

July 2017;18(7):596-600 


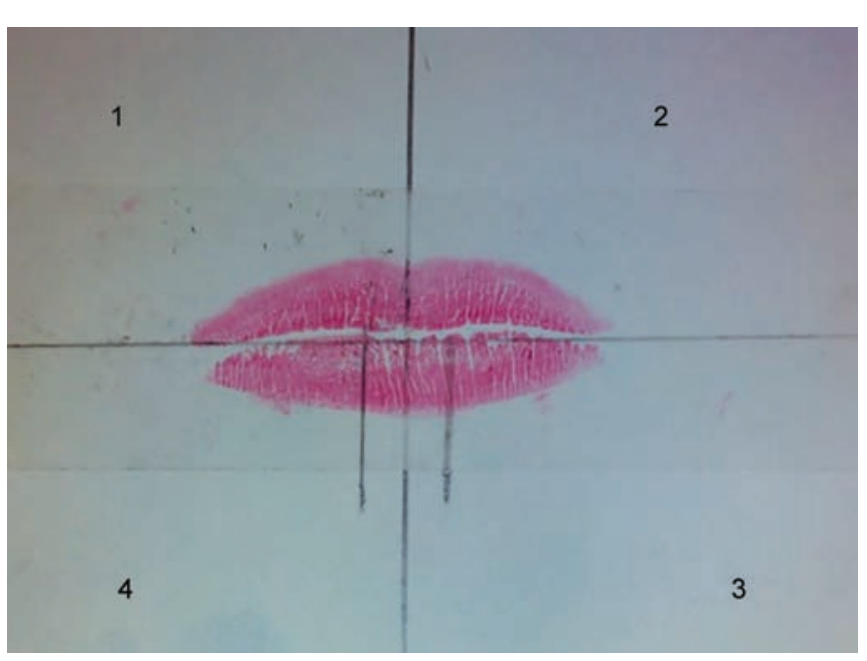

Fig. 2: Analysis of lip print patterns

middle region of the lower lip (10 $\mathrm{mm}$ wide) was used for analysis because this portion is seen in most of the traces. ${ }^{7}$ Each lip print pattern was determined as per following classification based on Suzuki and Tsuchihashi (Fig. 3).

- Type I: Straight grooves across the whole lips

- Type I': Similar to Type I, but grooves do not cover the whole lip

- Type II: Branched Y-shaped pattern

- Type III: Crisscross pattern

- Type IV: Reticular, typical checkered pattern, and fence like

- Type V: Undetermined ${ }^{8}$

\section{Identification of Blood Group}

Blood groups of the individuals were identified by the slide method, i.e., by mixing a sample of blood placed on
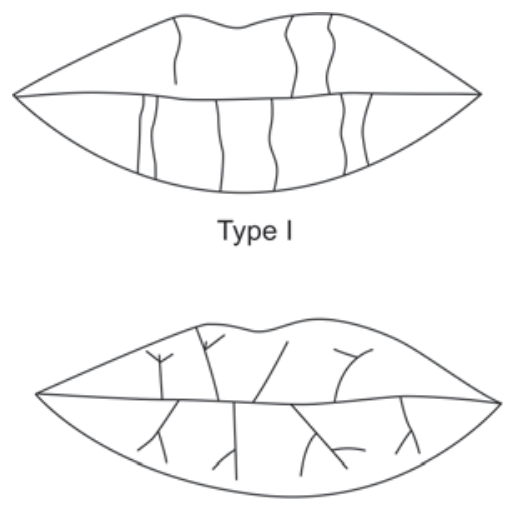

Type II

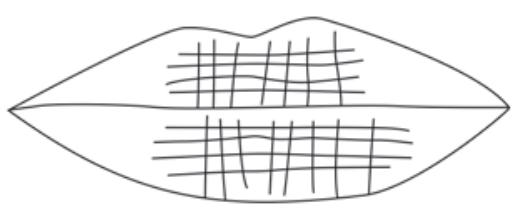

Type IV the glass slide with anti-A and anti-B sera. Agglutination of the sample after mixing with anti-A is blood group A; likewise, agglutination reaction with anti-B is blood group $B$; if no reaction is seen then the blood group is $\mathrm{O}$; and positive in both antisera then blood group is taken as $\mathrm{AB}$ blood group. Similarly, agglutination with Rh antigen is considered $\mathrm{Rh}+$ or otherwise as $\mathrm{Rh}-{ }^{9}$

Obtained data were tabulated in MS Excel sheet and chi-square test in Statistical Package for the Social Sciences was used for statistical analysis.

\section{RESULTS}

In present study, it was seen that no second individual has similar lip prints, thereby confirming the uniqueness of lip prints. In the present study, the most common lip print pattern was type IV $(\mathrm{n}=34)$ followed by II $(\mathrm{n}=26)$, III $(\mathrm{n}=14), \mathrm{I}(\mathrm{n}=14), \mathrm{V}(\mathrm{n}=4)$, and I' $(\mathrm{n}=1)$ as shown in Graph 1.

As shown in Graph 2, the most common blood group found in this study was $B+(n=28)$; next common is $A+$ $(\mathrm{n}=26), O+(\mathrm{n}=25), O-(\mathrm{n}=4)$, and $A B+(\mathrm{n}=2)$.

It was seen that in people having $\mathrm{B}+$ blood group, predominant pattern of lip print seen was Type IV; next common is Types II, III, I, and V and in people having blood group O+. Type II is the most commonly seen lip print pattern followed by Types III, IV, I, and V. In individuals with blood group I+, common pattern is Type IV; next common are Types II, III, I, and V. In individuals having blood group $\mathrm{AB}+$, lip print pattern seen was Type II and in individuals having $\mathrm{O}-$ blood group, common pattern seen is Type IV followed by Type II. Statistical association between blood groups and lip prints was
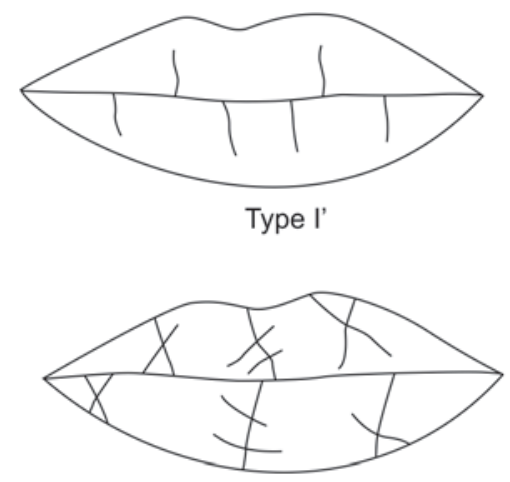

Type III

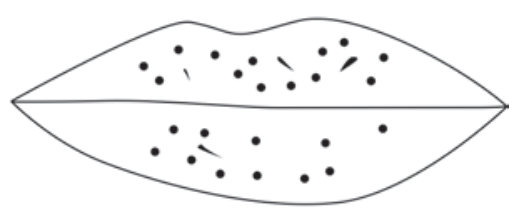

Type V

Fig. 3: Suzuki and Tsuchihashi classification of lip prints 


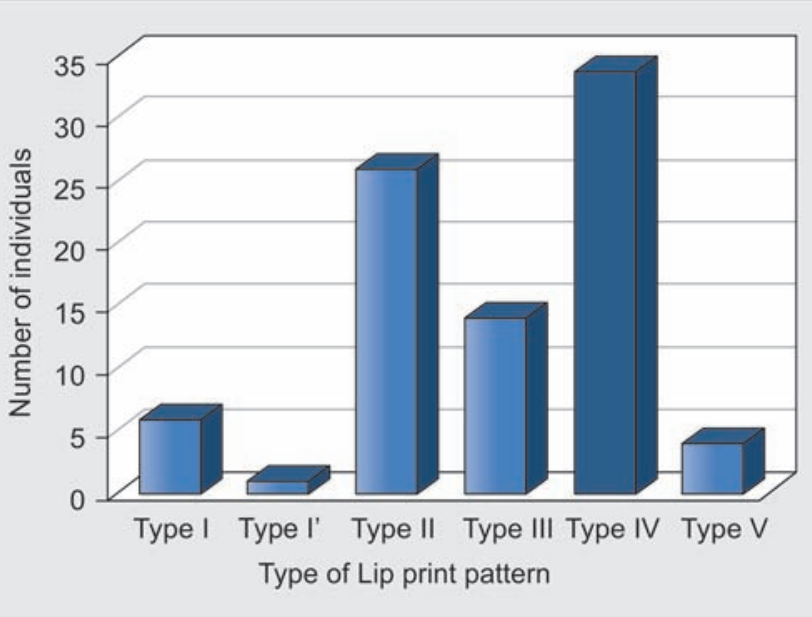

Graph 1: Distribution of lip print patterns among the study population

Table 1: Association between lip print patterns and blood groups

\begin{tabular}{lllllll}
\hline & \multicolumn{5}{c}{ Blood group } \\
\cline { 2 - 6 } Lip prints & $B+$ & $O+$ & $A+$ & $A B+$ & $O-$ & $\chi^{2}$ value \\
\hline Type I & 2 & 2 & 2 & 0 & 0 & 14.2 \\
Type I' & 1 & 0 & 0 & 0 & 0 & \\
Type II & 7 & 9 & 7 & 2 & 1 & \\
Type III & 3 & 6 & 5 & 0 & 0 & \\
Type IV & 14 & 6 & 11 & 0 & 3 & \\
Type V & 1 & 2 & 1 & 0 & 0 & \\
p-value & 0.04 & & & & & \\
\hline
\end{tabular}

found to be significant $(p=0.04$; Table 1). Based on the results of the study, given hypothesis is accepted.

In the present study, few blood groups were not considered for statistical analysis because there were nil individuals with these groups.

\section{DISCUSSION}

The first person to describe the use of lip prints in person identification was Kasprzak..$^{10}$ Among the various tools available to a forensic expert, cheiloscopy is a relatively newer one. Studies on these individuals have already provided useful information, but still there are few lacunas in the use of cheiloscopy, such as standardized method to record and analyze cheiloscopic prints, its association with other identification features, such as age, sex, and blood groups. Hence, this study was done to identify the correlation between lip print patterns and blood groups.

The predominant pattern in the present study was Type IV (32.5\%); next common is Type II ( $28.5 \%)$ and Type III $(17.5 \%)$, which are in accordance with the studies of Ashwinirani et $\mathrm{al}^{5}$ and Verghese et $\mathrm{al}^{11}$ and in contrast to the studies of Tsuchihashi ${ }^{12}$ and Vahanwala and Parekh. ${ }^{13}$

In the current study, it was seen that in individuals with $\mathrm{B}+, \mathrm{A}+$, and $\mathrm{O}-$ blood group, predominant lip print

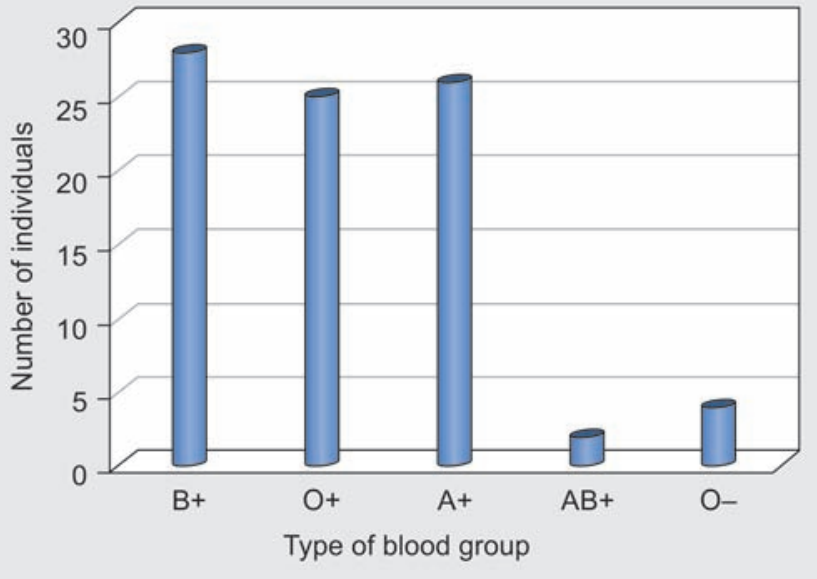

Graph 2: Distribution of blood groups among the study population

pattern was Type IV, and in individuals with blood group $\mathrm{O}+, \mathrm{AB}+$ common lip print pattern was Type II, which is in contrast with studies conducted by Ashwinirani et $\mathrm{al}^{5}$ and Patel et $\mathrm{al}^{14}$ where Type II was the most common pattern in individuals having $\mathrm{B}+, \mathrm{AB}+$, and $\mathrm{O}+$, whereas in person with $\mathrm{A}+$, the common pattern is Type IV.

In the present study, significant correlation was seen in lip print patterns and $\mathrm{ABO}$ blood groups; this might be due to the fact that both the lip prints and blood groups are genetically determined and developed during early fetal life. This contrasts with studies conducted by Verma et $\mathrm{al}_{,}{ }^{15}$ Telagi et $\mathrm{al}_{,}{ }^{16}$ and Karim and $\mathrm{Gupta}^{17}$ in various parts of India.

\section{CONCLUSION}

This study analyzed the lip print patterns with the blood groups of the individuals and was found to have significant association between lip prints and blood groups. Therefore, we can easily predict the blood group of persons with the help of her/his lips prints and both together can be used to identify a person. Although the present study has certain limitations, such as small sample size, results obtained in the present study do open a small window to a vast unventured field.

\section{REFERENCES}

1. Budowle B, Bieber FR, Eisenberg AJ. Forensic aspects of mass disasters: strategic considerations for DNA-based human identification. Leg Med (Tokyo) 2005 Jul;7(4):230-243.

2. Sivapathasundharam B, Prakash PA, Sivakumar G. Lip prints (cheiloscopy). Indian J Dent Res 2001 Oct-Dec;12(4):234-237.

3. Kaul R, Padmashree SM, Shilpa PS, Sultana N, Bhat S. Cheiloscopic patterns in Indian population and their efficacy in sex determination: a randomized cross-sectional study. J Forensic Dent Sci 2015 May;7(2):101-106.

4. Khanapure SC, Jain J, Anand SR, Supreetha S, Abhishek KN, Shilpa M. Cheiloscopy: the study of lip prints in relation to 
gender and geographic distribution. Int J Sci Study 2014; 2(9):21-26.

5. Ashwinirani SR, Suragimath G, Sande AR, Kulkarni P, Nimbal A, Shankar T, Gowd TS, Shetty PK. Comparison of lip print patterns in two Indian subpopulations and its correlation in ABO blood groups. J Clin Diagn Res 2014 Oct;8(10):ZC40-ZC43.

6. Srilekha N, Anuradha A, Srinivas GV, Devi RS. Correlation among lip print pattern, finger print pattern and abo blood group. J Clin Diagn Res 2014 Mar;8(3):49-51.

7. Sharma P, Saxena S, Rathod V. Cheiloscopy: the study of lip prints in sex identification. J Forensic Dent Sci 2009 Jan;1(1):24-27.

8. Rastogi P, Parida A. Lip prints - an aid in identification. Aust J Forensic Sci 2011 Oct;44:1-8.

9. National Institute of Biologicals. Guidance manual on "ABO and Rh blood grouping". Uttar Pradesh (India): National Institute of Biologicals; 2013. p. 2-31. [cited 2017 Feb 15]. Available from: http://www.nib.gov.in/guidance_document/Guidance_manucal_QC_ABO_Rh_blood_grouping 26_03_2013.pdf.
10. Kasprzak J. Possibilities of cheiloscopy. Forensic Sci Int 1990 May-Jun;46(1-2):145-151.

11. Verghese AJ, Somasekar M, Umesh BR. A study on lip types among the people of Kerala. J Indian Acad Forensic Med 2010 Jan;32(1):6-7.

12. Tsuchihashi Y. Studies on personal identification by means of lip prints. Forensic Sci 1974 Jun;3(3):233-248.

13. Vahanwala SP, Parekh BK. Study of lip prints as an aid to forensic methodology. J Forensic Med Toxicol 2000 Jan;17(1):12-18.

14. Patel S, Paul I, Madhusudan AS, Gayathri R, Sowmya GV. A study of lip prints in relation to gender, family and blood group. Int J Oral Maxillofac Pathol 2010 Nov;1(1):4-7.

15. Verma P, Sachdeva SK, Verma KG, Saharan S, Sachdeva K. Correlation of lip prints with gender, $\mathrm{ABO}$ blood groups and intercommissural distance. N Am J Med Sci 2013 Jul;5(7):427-431.

16. Telagi N, Mujib A, Spoorthi BR, Naik R. Cheiloscopy and its patterns in comparison with $\mathrm{ABO}$ blood groups. J Forensic Dent Sci 2011 Jul-Dec;3(2):77-80.

17. Karim B, Gupta D. Cheiloscopy and blood groups: aid in forensic identification. Saudi Dent J 2014 Oct;26(4):176-180. 